\title{
Identification of Genomic Heterogeneity among Lactococcus lactis Strains by Plasmid Profiling, PFGE and 16S rDNA Sequence Analysis
}

\author{
OZLEM GUNAY-ESIYOK ${ }^{1}$, NEFISE AKCELIK ${ }^{1}$ and MUSTAFA AKCELIK ${ }^{1,2}$ \\ ${ }^{1}$ Ankara University, Biotechnology Institute Central Laboratory, 06110 Besevler, Ankara, Turkey \\ ${ }^{2}$ Ankara University, Faculty of Science, Biology Department, 06100 Tandogan, Ankara, Turkey
}

Submitted 16 October 2013, revised 18 November 2013, accepted 5 December 2013

\begin{abstract}
Lactococcus lactis strains are used commonly as starters, which contribute to desirable flavour and texture properties known as strainspecific, in dairy industry. Genomic heterogeneity of $30 \mathrm{~L}$. lactis strains originating from Turkey and characterized phenotypically were investigated in this study. Plasmid profiling, PFGE and $16 \mathrm{~S}$ rDNA sequence analyses were performed to determine the genetic variability of strains. High degree of heterogeneity was detected among the L. lactis strains. Plasmid profiles of strains showed that compared to the plasmid free control strains, namely; L. lactis subsp. lactis IL1403 and L. lactis subsp. cremoris MG1614, all tested strains carried one to ten plasmids with molecular size ranging from 1.5 to $41.5 \mathrm{~kb}$. The fingerprints of strains obtained by PFGE from digestion with ApaI, SmaI and I-CeuI restriction endonucleases of chromosomal DNA's were compared with each other. All strains out of four were grouped into a large cluster A with at least 44\% similarity level. The other four strains formed a minor cluster B, distinctively different from major cluster A. PFGE results were confirmed by $16 \mathrm{~S}$ rDNA sequence analysis and strains included in cluster B were identified as members of different species. These results suggested that morphologic and biochemical methods should be verified by reliable molecular approaches for the purpose of strain typing. Also, PFGE was found suitable to determine genomic differentiations among inter- and intra species.
\end{abstract}

Ke y w ord s: Lactococcus lactis, genomic heterogeneity, plasmid profiling, PFGE, 16 S rDNA sequencing

\section{Introduction}

Lactococcus (L.) lactis is a Gram-positive, mesophilic bacterium which can be isolated from various environments such as vegetables, plant surfaces, raw milk and milk products (Nomura et al., 2006; Salama et al., 1995; Ulrich and Müller, 1998). L. lactis is regarded as the most famous member of the lactic acid bacteria with low $\mathrm{G}+\mathrm{C}$ content, and used as a starter culture in commercial milk productions. Due to the fact that it is the main component of fermented milk products, e.g., soft and hard cheeses, butter, sour creams and yoghurt, L. lactis strains have a great importance for dairy industry and economy, as well (Fernandez et al., 2011; Parente and Cogan, 2004). While this species is divided into 4 subspecies (subsp. lactis, cremoris, hordniae and tructae), only L. lactis subsp. lactis and L. lactis subsp. cremoris provide flavour and texture compounds for dairy products in industrial processes (Odamaki et al., 2011; Perez et al., 2010). In addition, L. lactis subsp. lactis has a biovariety called L. lactis subsp. lactis biovar diacetylactis, which can transform citrate into diacetyl as different from the other starter lactococci (Rademaker et al., 2007; Schleifer et al., 1985).

From the past to the present, the subdivision of L. lactis species is performed in view of phenotypic properties. L. lactis subsp. lactis is distinguished from L. lactis subsp. cremoris with respect to deamination of arginine and growth at $40^{\circ} \mathrm{C}$, at $\mathrm{pH} 9.2$, in $4 \% \mathrm{NaCl}$ (Mundt, 1986). However, it is accepted that these classification methods aren't sufficient to differentiate between the strains and to accurately find taxonomic positions (Botina et al., 2006; Holzapfel et al., 2001). Morphologic discrimination methods are rarely considered as they have poor reproducibility and discriminatory power (Farber 1996; Rantsiou and Cocolin, 2006; Tran et al., 2011), and moreover they do not express any information about the bacterial genome (Mohania et al., 2008). Therefore, the results obtained from phenotypic tests should be confirmed by molecular typing methods (Charteris et al., 1997; Giraffa and Neviani, 2000; Holzapfel et al., 2001; McCartney, 2002; O'Sullivan, 1999). Unfortunately, it was proved by previous studies that phenotypic and genotypic identification of

\footnotetext{
* Corresponding author: M. Akcelik, Ankara University, Faculty of Science, Biology Department, 06100 Tandogan, Ankara, Turkey; phone: +90 312 2126720/1056; fax: +90 312 2232395; e-mail: akcelik@science.ankara.edu.tr
} 
lactococcal strains didn't correspond with each other. This situation causes confusion in the taxonomy of L. lactis (Godon et al., 1992; Holzapfel et al., 2001; Kelly et al., 2010; Psoni et al., 2007; Salama et al., 1995).

In the dairy industry, development of new commercial products, which have unique sensorial qualities, is always demanded. It is known that aroma compounds of strains are encoded by extrachromosomal plasmid DNAs (Botina etal., 2006; MacKay, 1983). Besides, many researchers have detected that flavour formation abilities of starters are notably strain-specific (Ayad et al., 1999; Marilley and Casey, 2004; Smit et al., 2000; van Kranenburg et al., 2002; Williams et al., 2001). In order to improve desirable industrial features of substantial starters and develop new industrial strains which will be able to produce different aroma compounds in commercial products, L. lactis strains should be well-characterized and evaluated individually by using molecular approaches. Over the last two decades, a lot of strain-specific DNA-based methods for identification and classification of bacteria have been developed such as pulsed-field gel electrophoresis (PFGE), ribotyping, randomly amplified polymorphic DNA (RAPD) and amplified fragment length polymorphism (AFLP). However, PFGE was found to be more sensitive than the other techniques to differentiate strains based on the principle of separating macrorestriction DNA fragments obtained from restriction enzyme digests (O'Riordan and Fitzgerald, 1997; Yeung et al., 2004). Furthermore, it was also demonstrated by many previous studies that this technique was suitable to distinguish closely related L. lactis strains individually (Delgado and Mayo, 2004; Mannu etal., 1999; Mannu et al., 2000; Mannu and Paba, 2002; Tanskanen et al., 1990; Ward et al., 2004). The aim of this study is to determine the genetic heterogeneity of 30 L. lactis strains originating from Turkey by using a combination of three molecular typing methods; plasmid profiling, PFGE and $16 S$ rDNA sequencing.

\section{Experimental}

\section{Materials and Methods}

Bacterial strains, media and culture conditions. 30 of Lactococcus lactis strains, which were collected from raw milk and traditional fermented milk products in different regions of Turkey (Akcelik et al., 2000) and characterized by using biochemical and phenotypical tests at subspecies level previously (Ozkalp et al., 2007), were obtained from Prokaryote Genetics Laboratory Culture Collection of Ankara University. These strains were named according to their phenotypic profiles. 10 of them were found at L. lactis subsp. lactis pheno- type, 14 of them were found at $L$. lactis subsp. lactis biovar diacetylactis phenotype, and finally 6 of them were found at L. lactis subsp. cremoris phenotype as could be seen in Table I. Except for M10, BLC21 and LL171 strains which are isolated from white cheese, all other 27 strains originated from raw milk. Also, plasmid-free L. lactis subsp. lactis IL1403 and L. lactis subsp. cremoris MG1614 were used as control strains, and L. lactis subsp. lactis ATCC 7962 was used as a standard. All strains were grown in M17 broth (Merck, Germany) medium at $30^{\circ} \mathrm{C}$ for $18 \mathrm{~h}$ over the study. Stock cultures were kept in $40 \%$ glycerol at $-80^{\circ} \mathrm{C}$.

Plasmid profiling. Extrachromosomal plasmid DNAs of L. lactis strains were extracted as described by Anderson and McKay, (1983), and separated by electrophoresis on $0.7 \%$ agarose gels in $1 \times$ TAE buffer at $100 \mathrm{~V}$. Supercoiled DNA ladder (Sigma-Aldrich, USA) was used as a molecular weight marker to determine plasmid sizes. Gels were stained in $1 \times$ TAE containing $0.2 \mu \mathrm{g} / \mathrm{ml}$ ethidium bromide, and visualized under UV light.

Preparation of DNA embedded agarose plugs, restriction digestion and PFGE analysis. PFGE-CHEFDR III applications guide protocol (Bio-Rad, USA) was modified for isolation intact genomic DNA's of strains before PFGE analysis. An overnight L. lactis cultures were diluted in fresh broth until they were standardized between 0.5 and 1 at $\mathrm{OD}_{600^{\circ}}$, and then harvested by centrifugation $\left(10.000 \times \mathrm{g}, 5 \mathrm{~min}, 4^{\circ} \mathrm{C}\right)$. Pellets were washed twice with CS-Buffer (10 mM Tris pH: 7.0, $20 \mathrm{mM} \mathrm{NaCl}$, 50 mM EDTA pH: 8.0) and resuspended in $100 \mu$ of the same buffer. Equal volumes of $2 \%$ low melting grade agarose (BioShop, Canada) was mixed in resuspension. $100 \mu \mathrm{l}$ mixture was transferred into acrylic disposable plug molds $(10 \mathrm{~mm} \times 5 \mathrm{~mm} \times 1.5 \mathrm{~mm})$ and stored till polymerization at $4^{\circ} \mathrm{C}$. Cells embedded in agarose were lysed in situ with lysis solution $(30 \mathrm{mM}$ Tris $\mathrm{pH}$ : 8.0, $5 \mathrm{mM}$ EDTA pH: $8.0,50 \mathrm{mM} \mathrm{NaCl}, 10 \mathrm{mg} / \mathrm{ml}$ lysozyme) for $4 \mathrm{~h}$ at $37^{\circ} \mathrm{C}$. Following the incubation agarose plugs were washed with $1 \times$ TE buffer $(50 \mathrm{mM}$ EDTA, $20 \mathrm{mM}$ Tris $\mathrm{pH}$ : 8.0) so as to eliminate lysis solution. Afterwards, plugs were treated with Proteinase K solution (100 mM EDTA pH: 8.0, $0.2 \%$ sodium deoxycholate, $1 \%$ sarkosyl, $1 \mathrm{mg} / \mathrm{ml}$ proteinase $\mathrm{K}$ ) for $18 \mathrm{~h}$ at $50^{\circ} \mathrm{C}$. Agarose plugs containing intact genomic DNA were washed for $30 \mathrm{~min}$ at $50^{\circ} \mathrm{C}$; four times with $1 \times \mathrm{TE}$ by adding $1 \mathrm{mM} \mathrm{NaCl}$, twice with $1 \times$ TE by adding $1 \mathrm{mM}$ PMSF (phenylmethylsulfonyl fluoride), twice with $1 \times \mathrm{TE}$ and finally twice with $0.1 \times \mathrm{TE}$, respectively.

Each DNA embedded agarose plug was cut into four slices. These slices were treated with ApaI, SmaI and I-CeuI restriction endonucleases, separately. Slices were digested with $25 \mathrm{U}$ of $A p a \mathrm{I}$ at $37^{\circ} \mathrm{C}$ and $30 \mathrm{U}$ of $S m a \mathrm{I}$ at $30^{\circ} \mathrm{C}$ for $16 \mathrm{~h}$ in $100 \mu \mathrm{l}$ of the $1 \times$ SE-Buffer Y (SibEnzyme, Russia). DNA digestion with $10 \mathrm{U}$ of I-CeuI (New 
England Biolabs, UK) was performed also at $37^{\circ} \mathrm{C}$ for $3 \mathrm{~h}$ in $100 \mu \mathrm{l}$ solution consisting of the enzyme buffer and BSA. After digestions, slices were equilibrated in $0.5 \times \mathrm{TBE}$ buffer for $30 \mathrm{~min}$.

Macrorestriction DNA patterns were resolved in $1 \%$ pulsed-field certified agarose (BioShop, Canada) in $0.5 \times$ TBE buffer by PFGE-CHEF-DR III System (BioRad, USA). Lambda ladder PFG Marker (New England Biolabs, UK) was used as a molecular size standard. Electrophoresis was performed at $14^{\circ} \mathrm{C}$ and at $120^{\circ}$ angle for three enzymes. For $S m a I$ digests, pulse times ranged from 0.5 to $3 \mathrm{~s}$ for $5 \mathrm{~h}$, from 5 to $25 \mathrm{~s}$ for $6 \mathrm{~h}$ and from 40 to $125 \mathrm{~s}$ for $8 \mathrm{~h}$ at $6 \mathrm{~V} / \mathrm{cm}$. Electrophoresis was run at $5 \mathrm{~V} / \mathrm{cm}$ for both $A p a \mathrm{I}$ and I-CeuI. For ApaI digests, switching times ranged from 0.1 to $5 \mathrm{~s}$ for $7 \mathrm{~h}$, from 5 to $35 \mathrm{~s}$ for $10 \mathrm{~h}$ and from 40 to $125 \mathrm{~s}$ for $5 \mathrm{~h}$, on the other hand for I-CeuI digests, switching times ranged from 5 to $125 \mathrm{~s}$ for $22 \mathrm{~h}$. After electrophoresis, agarose gels were stained with ethidium bromide $(10 \mu \mathrm{g} / \mathrm{ml})$, visualized under UV light, and documented as TIFF files.

Statistical analysis. Plasmid and PFGE gel images were digitized by Gel Logic 200 Imaging System (Kodak Company). Grouping of the plasmid and PFGE patterns were performed by unweighted pair group method using arithmetic average (UPGMA) cluster analysis (Sneath and Sokal, 1973). The similarity matrix was calculated on the basis of Pearson correlation coefficient (r) for plasmid profiles and Dice correlation coefficient for PFGE patterns by NTSYS-pc 2.20 (Rohlf, 1993) computer software.

Genomic DNA isolation, 16S rRNA gene amplifications and sequencing. Genomic DNAs of L. lactis strains were extracted by using 'Genomic DNA isolation from Gram-positive bacteria' protocol published by Park, (2007), and stored at $-20^{\circ} \mathrm{C}$. Oligonucleotide primers described by Beasley and Saris, (2004) were used for 16S rRNA gene amplifications (F: 5'-CCGTCAATTCCTTTGAGTTT-3') (R: 3'-AGAGTTTGATCCTGGCTCAG-5'). PCR was carried out by Thermocycler (Techne, TC-512) in $0.2 \mu \mathrm{l}$ reaction tubes with $50 \mu \mathrm{l}$ final mixture volume. Each reaction mixture contained $20 \mathrm{pmol} / \mu \mathrm{l}$ concentration of $\mathrm{F}$ and $\mathrm{R}$ primers, $2 \mathrm{mM}$ dNTP mix (Fermentas, Finland), $10 \mu \mathrm{l}$ of $10 \times$ PCR buffer, $25 \mathrm{mM} \mathrm{MgCl}_{2}, 5 \mathrm{U} / \mu \mathrm{lTaq}$ DNA polymerase (Promega, USA) and $3 \mu$ lof genomic DNA. Amplification was performed according to the following program: preheating for $5 \mathrm{~min}$ at $94^{\circ} \mathrm{C} ; 30$ cycles of denaturation for $1 \mathrm{~min}$ at $94^{\circ} \mathrm{C}$; annealing for $15 \mathrm{~s}$ at $54^{\circ} \mathrm{C}$; extension for $1 \mathrm{~min}$ at $72^{\circ} \mathrm{C}$ and a final terminal extension for $10 \mathrm{~min}$ at $72^{\circ} \mathrm{C}$. PCR products were examined by $1 \%$ agarose gel electrophoresis in $1 \times$ TAE buffer at $100 \mathrm{~V}$. $1 \mathrm{~kb}$ DNA ladder (Solis BioDyne, Estonia) was used as a molecular size standard. Amplicons were purified by using Wizard-SV Gel and PCR Clean-Up System (Promega, USA) and sent for sequencing to REFGEN-
Biotechnology (METU, Technopolis). Results of the sequencing were aligned by NCBI-BLAST (Basic Local Alignment Search Tool) program to determine the closest known relatives of the $16 \mathrm{~S}$ rDNA sequence obtained (data not shown).

\section{Results and Discussions}

Genotypic diversity of all $30 \mathrm{~L}$. lactis strains originated from Turkey was determined by plasmid profiling, PFGE and $16 \mathrm{~S}$ rDNA sequence analysis. Results of plasmid profiling showed that except for plasmid-free control strains (IL1403 and MG1614), all strains harboured 1 to 10 plasmids with an apparent molecular size ranging from 1.5 to $41.5 \mathrm{~kb}$ (Table I). MBLD 59 and MBLD 63 strains contain largest plasmid in size $41.5 \mathrm{~kb}$, whereas MBLD 36 has the smallest one in size $1.5 \mathrm{~kb}$. Fujita et al. (1984) reported that L. lactis isolates generally carry plasmids whose number vary about 1 to up to 12 with a molecular weight 1.5 from $80 \mathrm{~kb}$. It was detected within a recent study of Fallico et al., (2012) that each lactococcal strain contained from 2 to 10 plasmid patterns ranging in size between 2 and $80 \mathrm{~kb}$. We also obtained identical plasmid profile results in this study for L. lactis strains originated from Turkey. Cluster analysis of plasmid profiles demonstrated the genetic variability among isolates (Fig. 1). According to the dendogram, all strains out of MBLD 63 were grouped in two main clusters with about 55\% similarity level. It was found that MBLD 63 has unique plasmid profile, so it wasn't located in any cluster. While cluster A branched 7 subgroups for 27 strains, cluster B was composed of only 3 strains, namely; MBLC 47, MBLC 50 and MBLD 54 with a higher similarity level than cluster A. Only MBLC 38 and LL171 have the same plasmid content with one plasmid in size $29.3 \mathrm{~kb}$. Except for these strains, all isolates displayed exactly different plasmid profiles.

Boucher etal. (2001) reported that commercial L. lactis strains can carry various plasmids which are required to develop important technological features such as lactose fermentation, proteolytic activities and phage resistance. L. lactis strains investigated in this study were considered as they can have important properties for dairy industry, owing to numerous plasmid contents of them. On the other hand, it was apparently seen that plasmid profiling wasn't sufficient to identify the strains at subspecies level. Besides, plasmid-free strains, such as IL1403 and MG1614, couldn't be evaluated by this technique. It is also known that plasmids are unstable genetic elements of bacteria, and they are also influenced quickly from environmental factors. They could be got or lost between intra- or inter species via horizontal transfer way (De Vuyst and Degeest, 
Table I

Plasmid contents of L. lactis strains originating from Turkey with their molecular weights

\begin{tabular}{|l|c|l|}
\hline \multicolumn{1}{|c|}{$\begin{array}{c}\text { Strain } \\
\text { Code }\end{array}$} & $\begin{array}{c}\text { Number } \\
\text { of } \\
\text { Plasmids }\end{array}$ & \multicolumn{1}{|c|}{ Molecular weight of Plasmids (kb) } \\
\hline MBLL 1 & 7 & $33.1,29.3,27.2,20.3,12.3,10.7,3.2$ \\
\hline MBLL 3 & 9 & $33.1,29.3,27.2,21.7,20.3,15.2,13.4,7,3.2$ \\
\hline MBLD 4 & 8 & $30.7,27.2,23.4,20.3,18.6,15.2,13.4,3.2$ \\
\hline MBLD 5 & 8 & $36.2,29.3,27.2,18.6,17.4,12.3,10.7,2.5$ \\
\hline MBLL 6 & 8 & $36.2,27.2,20.3,15.2,13.4,10.7,8,7$ \\
\hline MBLD 7 & 8 & $36.2,30.7,27.2,18.6,15.2,13.4,8,7$ \\
\hline MBLL 8 & 9 & $33.1,30.7,29.3,27.2,20.3,18.6,12.3,10.7,2.5$ \\
\hline MBLL 9 & 9 & $27.2,23.4,20.3,17.4,15.2,12.3,10.7,8,2.5$ \\
\hline MBLD 10 & 5 & $29.3,27.2,20.3,12.3,2.5$ \\
\hline MBLL 11 & 6 & $29.3,23.4,17.4,15.2,12.3,8,3.2$ \\
\hline MBLC 15 & 1 & 25.7 \\
\hline MBLD 17 & 9 & $33.1,30.7,27.2,25.7,18.6,17.4,10.7,9.2,2.5$ \\
\hline MBLD 19 & 8 & $27.2,25.7,21.7,13.4,12.3,10.7,7,5.5$ \\
\hline MBLD 21 & 9 & $33.1,30.7,25.7,21.7,18.6,10.7,7,5.5,2.5$ \\
\hline MBLL 25 & 4 & $25.7,23.4,15.2,10.7$ \\
\hline MBLL 26 & 7 & $30.7,25.7,15.2,13.4,10.7,8,5.5$ \\
\hline MBLL 27 & 8 & $30.7,25.7,18.6,15.2,13.4,10.7,8,7$ \\
\hline MBLD 35 & 9 & $30.7,27.2,23.4,20.3,12.3,10.7,9.2,5.5,4.6$ \\
\hline MBLD 36 & 7 & $30.7,23.4,15.2,8,3.2,2.5,1.5$ \\
\hline MBLC 38 & 1 & 29.3 \\
\hline MBLC 47 & 10 & $36.2,33.1,29.3,21.7,18.6,15.2,12.3,9.2,8,2.5$ \\
\hline MBLC 50 & 8 & $36.2,33.1,30.7,21.7,18.6,12.3,9.2,8$ \\
\hline MBLD 51 & 9 & $36.2,30.7,29.3,20.3,18.6,12.3,10.7,4.6,2.5$ \\
\hline MBLD 54 & 10 & $36.2,33.1,29.3,20.3,17.4,12.3,9.2,8,4.6,2.5$ \\
\hline MBLD 55 & 8 & $36.2,30.7,27.2,23.4,18.6,12.3,4.6,2.5$ \\
\hline MBLD 59 & 3 & $41.5,27.2,23.4$ \\
\hline MBLD 63 & 9 & $41.5,36.2,33.1,27.2,23.4,21.7,5.5,3.2,2.5$ \\
\hline BLC 21 & 1 & 27.2 \\
\hline LL171 & 1 & 29.3 \\
\hline M10 & 5 & $27.2,18.6,17.4,10.7,8$ \\
\hline ATCC 7962 & 4 & $38,30.7,27.2,18.6$ \\
\hline IL1403 & 0 & none \\
\hline MG1614 & 0 & none \\
\hline
\end{tabular}

a The name of strains was assigned according to phenotypical identifications. Expressions: MBLL and LL171: L. lactis subsp. lactis; MBLCBLC 21 and M10: L. lactis subsp. cremoris; MBLD: L. lactis subsp. lactis biovar diacetylactis.

1999; Dieye et al., 2001). In these cases, only typing by plasmid profiling is not so reliable. Thus, we made an elaborate research by using PFGE.

In order to assess the genetic diversity and relatedness among the L. lactis strains, 30 lactococcal isolates were exposed to PFGE. Sizes of PFGE-separated macrorestriction fragments obtained from SmaI and ApaI restriction digestion of control strain IL1403 were determined by Le Bourgeois et al. (1992), previously. MG1614 is a plasmid-free derivative of L. lactis subsp. cremoris MG1363 (Kelly et al., 2000) whose size of restriction fragment sizes were assigned by Le Bourgeois et al. (1995). The number of macrorestriction patterns obtained from SmaI digest of lactococcal strains was detected between 10 and 24, and each fragment varied from 3 to $950 \mathrm{~kb}$ in molecular weight (Fig. 2). Only three strains; namely MBLD 5, MBLD 10 and MBLD 17 had the same SmaI band profile. Therefore, these strains were regarded as the same strain. MBLD 21 was differed from them with only presence of a fragment $190 \mathrm{~kb}$ in size instead of $180 \mathrm{~kb}$. Consequently, these four strains were considered as having evolved from the same ancestor strain and are closely related. Other lactococcal strains formed unique SmaI band profiles. Cluster analysis of macrorestriction patterns generated by SmaI digestion of chromosomal DNAs revealed one major and minor group for 33 strains (Fig. 3). Cluster A was a major group including 29 strains with at least $44 \%$ similarity level and subdivided into 6 subgroups. It was apparently seen on the dendogram that strains, which were characterized phenotypically as subsp. lactis, were clustered usually together in clusters A1 and A2. In addition, strains characterized as biovar diacetylactis were grouped together in clusters A3, A4 and A5. Surprisingly, control strain MG1614 took place in cluster A5. This case made us think that MBLD 54, 55 and 59 get involved in cremoris genotype like MG1614. On the other hand, IL1403 and ATCC 7962 were grouped in cluster A2 with other subspecies lactis members. Cluster $\mathrm{B}$ was a minor group comprising just four strains, namely; MBLC 15, MBLC 18, BLC 21 and M10 at 54\% similarity level. In terms of low similarity rates among lactococcal strains, our results were similar with those from a study conducted by Psoni et al., (2007). On the contrary, based on the PFGE patterns of 47 lactococcal total DNA after digestion with SmaI restriction enzyme, Kahala et al. (2008) defined three major clusters at a similarity level of $75 \%$. Inconsistency between phenotypic and genotypic identification of a strain is a common situation in L. lactis taxonomy. In our study, we inferred that strains called MBLD 54, 55 and 59 belonged to the subspecies cremoris, although they exhibited similar phenotypic features with biovar diacetylactis. This situation was also encountered in a recent study conducted by Demarigny et al. (2011). They analysed 184 isolates by REP-PCR and PFGE in order to evaluate diversity of Lactococcus population in whey. Consequently, some of the strains were assigned to the L. lactis subsp. cremoris, despite the fact that they displayed similar phenotypic and REP-PCR profiles with subsp. lactis. In another study, Erkus-Kütahya et al., (2011) examined cluster analysis of 82 dairy and nondairy L. lactis isolates by AFLP. They observed that strains displaying both subsp. cremoris and subsp. lactis phenotype were grouped into the same cluster with a similarity level of $80 \%$ among strains. 


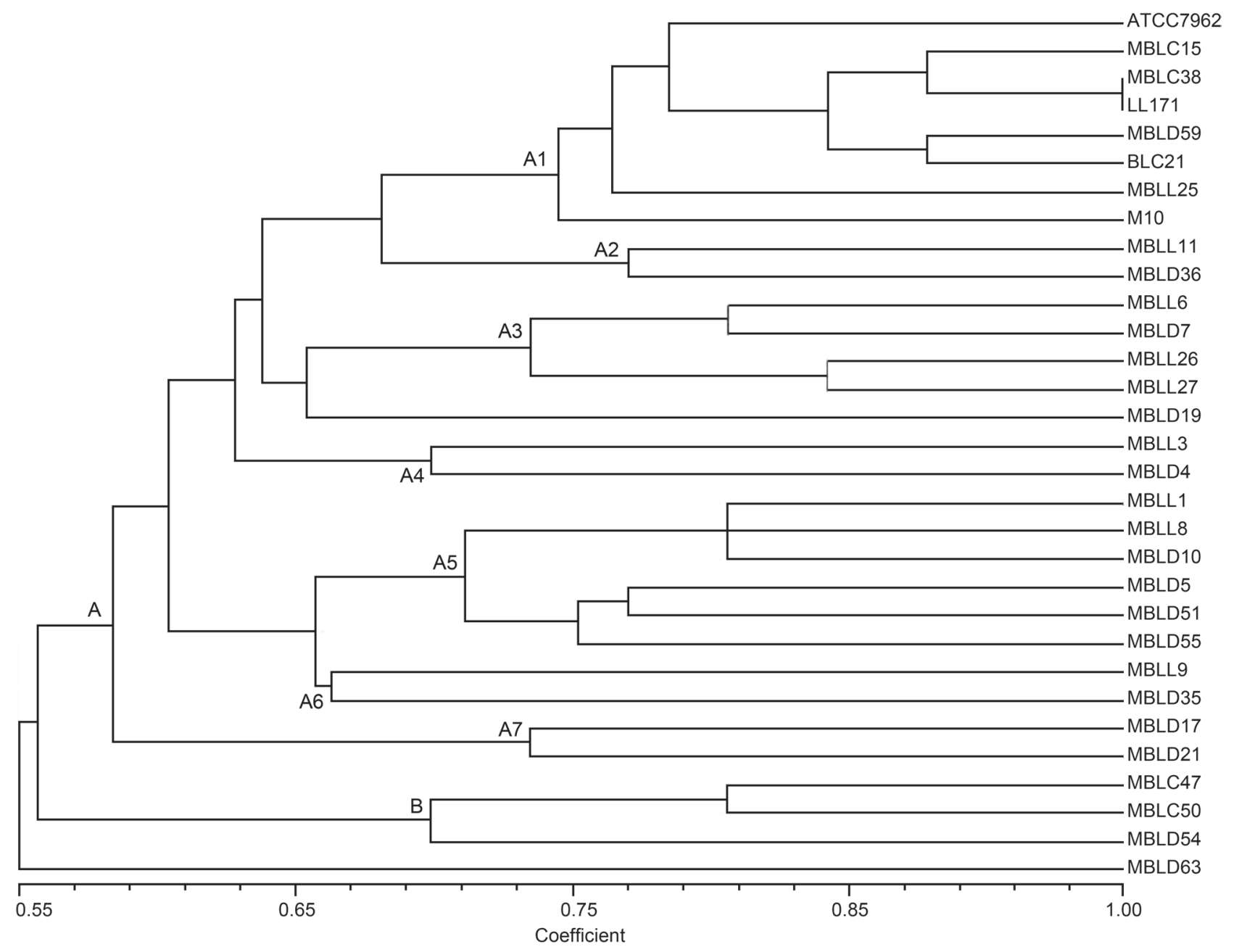

Fig. 1. Clustering of plasmid profiles of L. lactis strains by using UPGMA method based on Pearson correlation coefficient.

The macrorestriction fragments of L. lactis strains obtained from ApaI digestion ranged from 2 to $305 \mathrm{~kb}$ in size, and the number of restriction patterns for each strain varied from 15 to 24 . The PFGE profile of strains obtained from ApaI digestion appeared similar with SmaI results. Out of three isolates (BLC 21, MBLC 15 and MBLC 38), all strains were clustered into a large group with a minimal 65\% similarity level (data not shown). MBLD 10 and MBLD 17 exhibited the same ApaI band profile like SmaI digestion. However, it was found that under the electrophoretic conditions performed in this study, the use of restriction endonuclease SmaI gave better separated bands than ApaI for L. lactis strains originating from Turkey. The recognition sites of SmaI and ApaI endonucleases can be linked up linear plasmid regions integrating into the chromosome within evolutionary processes (Ward et al., 1993). Owing to the contribution of linear plasmids on the SmaI and ApaI macrorestriction patterns, I-CeuI was used to attain PFGE fragments purely originated from chromosomal DNA. I-CeuI is a homing endonuclease enzyme, digests only $23 \mathrm{~S}$ rDNA gene regions of the chromosome known as highly protected within the evolutionary processes (Liu et al., 1999). It is also known that $L$. lactis strains have six ribosomal operons with around $2.5 \mathrm{Mb}$ total chromosome length (Kelly et al., 2010; Le Bourgeois et al., 1992). Results obtained from SmaI and ApaI digestion were confirmed by using I- $\mathrm{CeuI}$ restriction endonuclease. The size of I- $\mathrm{CeuI}$ fragments of plasmid-free IL1403 was used as a molecular size standard previously described by Le Bourgeois et al. (1995). After I-Ceul restriction enzyme digestion of chromosomal DNAs of strains and PFGE treatment, it was observed that 15 of $L$. lactis strains originating from Turkey constituted different I-CeuI fragment numbers varying from 4 to 9 (Fig. 4). Moreover, the total chromosome size of isolates was found to be between 1.98 and $3.3 \mathrm{Mb}$. I-CeuI fragment sizes of strains were observed in Table II with complete chromosome length.

The results obtained from I-CeuI digestion were suspicious since resulting restriction fragments were not compatible with previous studies as regards L. lactis (Kelly et al., 2000; 2010; Le Bourgeois et al., 1995; 2000). 16S rDNA sequencing was applied to support results obtained from I-CeuI digestion. This technique was found as the best by Siezen et al. (2011) when it 

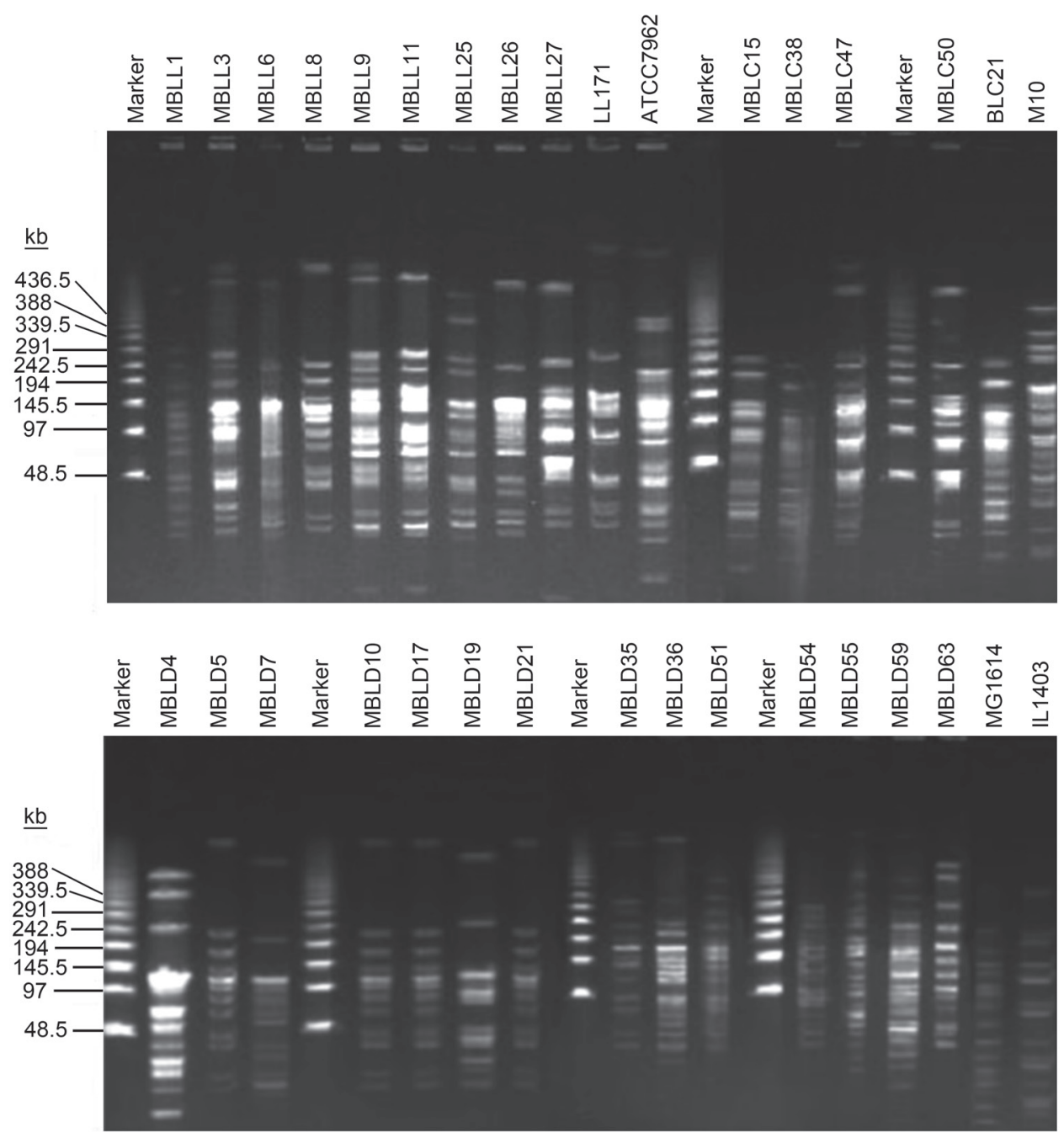

Fig. 2. PFGE patterns of SmaI-digested genomic DNA of L. lactis strains. Marker: Lambda Ladder PFG Marker (New England BioLabs).

was combined with other methods such as genotypic markers and selected phenotypic tests to describe diversity of $L$. lactis species. It was reported in another study conducted by Pillidge et al. (2009) that $16 \mathrm{~S}$ rDNA gene sequencing gave significant results for L. lactis when it was supported by PFGE results. In this study, we also combined $16 \mathrm{~S}$ rDNA sequence analyses with PFGE. 16S rRNA gene region of strains was amplified by using specific primers. Afterwards, amplicons, which were determined as $940 \mathrm{bp}$ in size for L. lactis, were sequenced (data not shown). After comparative $16 \mathrm{~S}$ rDNA analysis, it was undoubtedly detected that MBLC 15, MBLC 38 and BLC 21 strains, which generated four I-CeuI macrorestriction patterns and were identified previously as L. lactis subsp. cremoris according to phenotypic tests, are members of Streptococcus bovis whose natural habitat is cow udder. It was also determined that strain M10, which formed five I-CeuI fragments and was identified phenotypically as L. lactis subsp. cremoris, is in a subgroup of Enterococcus durans. The other 26 remained strains were identi- fied undoubtedly as L. lactis. The increase of ribosomal operon numbers of $L$. lactis strains originated from Turkey can be clarified with large plasmid integrations on recognition site of I-CeuI restriction endonuclease. Integration of large plasmids into chromosome occurs by way of horizontal gene transfers between the strains sharing the same biotope. Also, the increase or decrease of the fragment sizes can relate to gain or loss of moderate prophages, duplicated genes, number of repetitive sequences or mobile elements on chromosome. Such these chromosomal rearrangements could cause chromosomal differentiations of strains belonging to the same genetic lineage (Le Bourgeois et al., 2000). It was also reported by Passerini et al. (2010) that PFGE provides a means to monitor genome rearrangements (for instance large inversions or insertions/deletions of mobile genetic elements such as phages and genomic islands) rather than mutations within L. lactis species.

In this study, we used plasmid profiling, PFGE and $16 \mathrm{~S}$ rDNA sequencing in order to identify the heterogeneity and chromosomal diversity of 30 L. lactis strains 


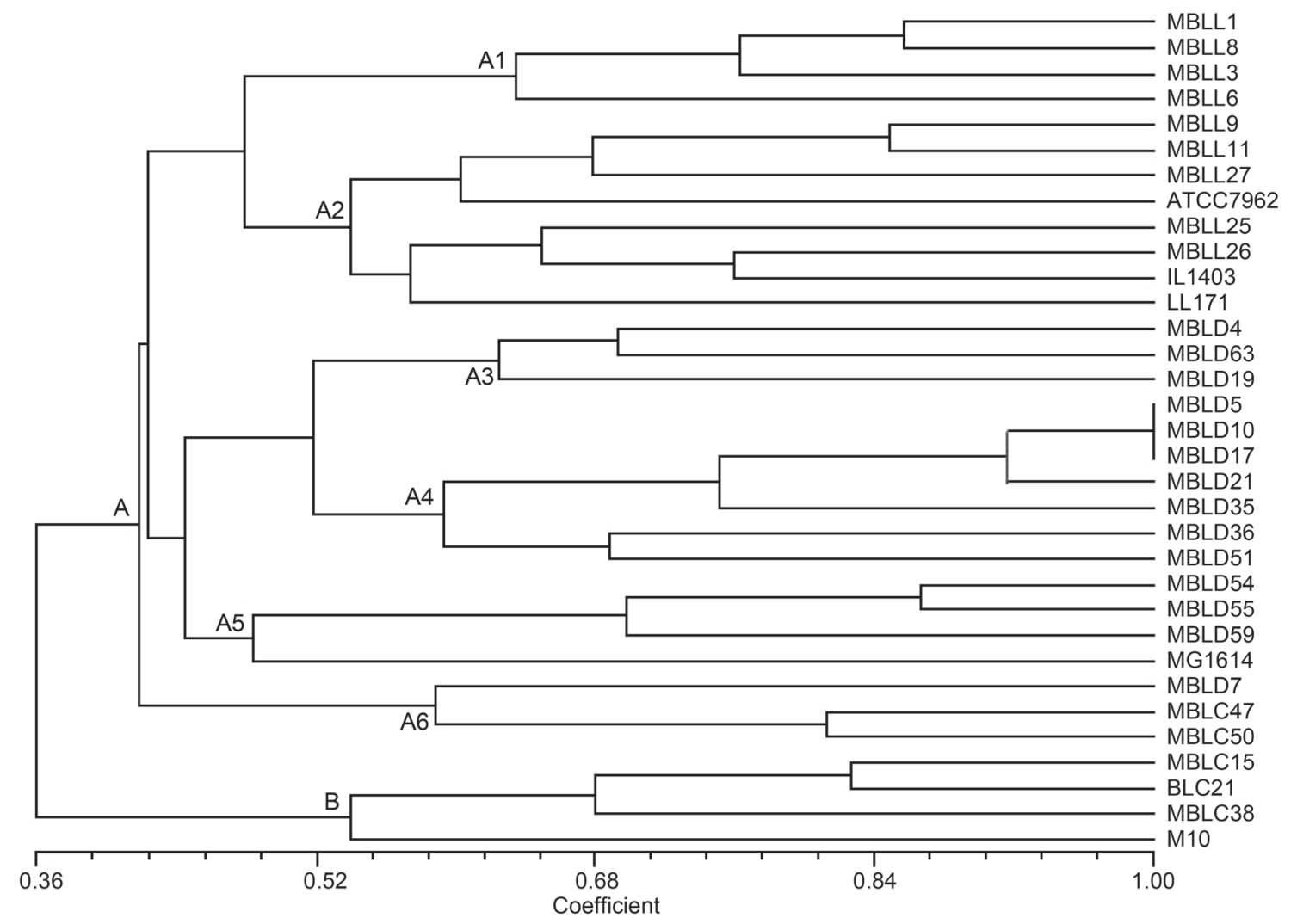

Fig. 3. Clustering of PFGE patterns obtained from SmaI digestion of chromosomal DNAs of L. lactis strains by using UPGMA method based on Dice correlation coefficient.

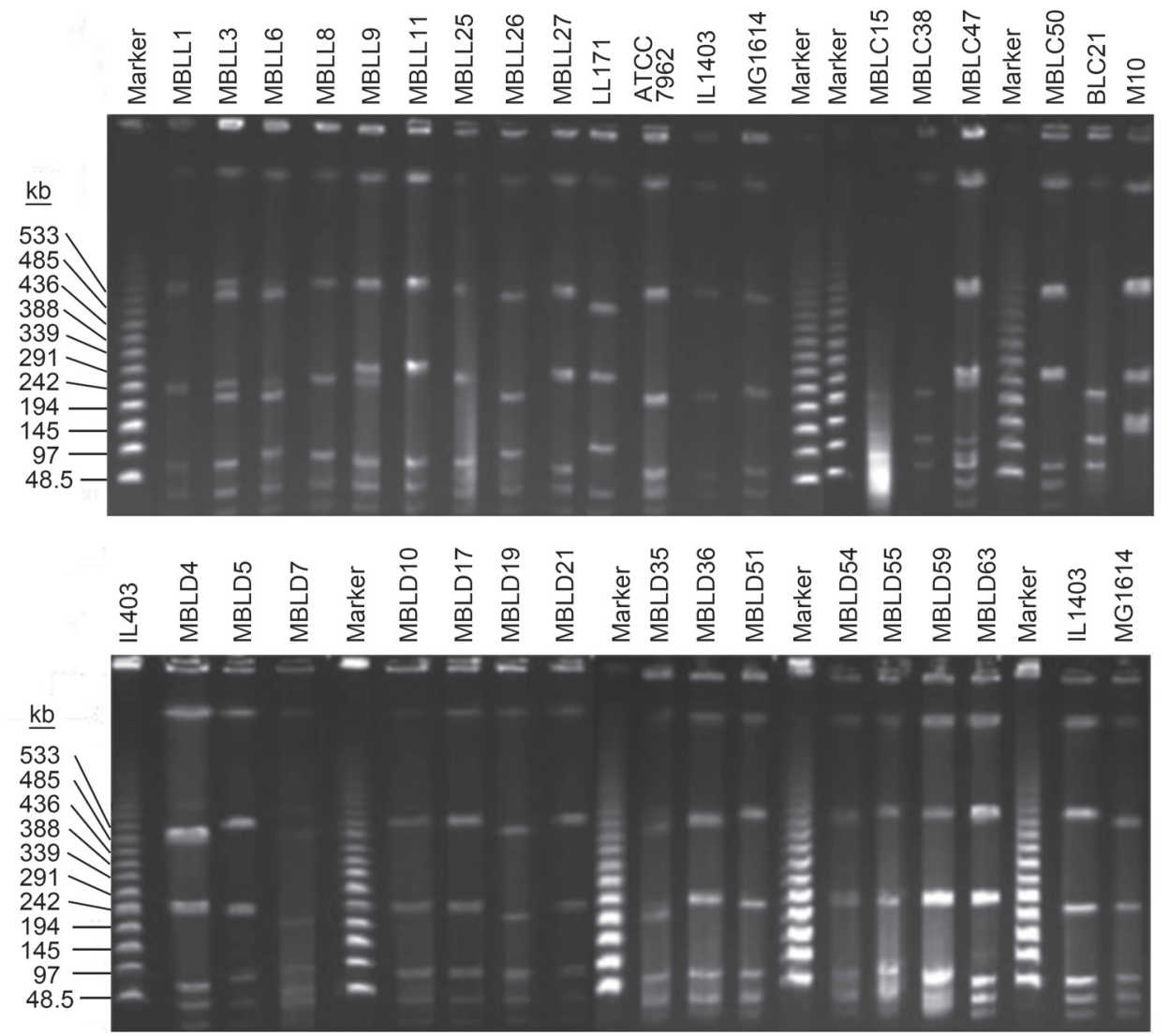

Fig. 4. PFGE patterns of I-CeuI-digested genomic DNA of L. lactis strains. Marker: Lambda Ladder PFG Marker (New England BioLabs). 
Table II

Size of I-CeuI restriction fragments and total chromosome length of L. lactis strains ${ }^{\alpha}$

\begin{tabular}{|c|c|c|}
\hline $\begin{array}{l}\text { Strain } \\
\text { Code }\end{array}$ & $\begin{array}{l}\text { Sizes of I-CeuI } \\
\text { fragments (kb) }\end{array}$ & $\begin{array}{c}\text { Chr. } \\
\text { Length }(\mathrm{kb})\end{array}$ \\
\hline MBLL1 & $1550-580-240-80-45-18$ & 2513 \\
\hline MBLL3 & $1550-580-530-260-230-87-45-18$ & 3300 \\
\hline MBLD4 & $1480-630-480-240-80-45-18$ & 2973 \\
\hline MBLD5 & $1480-560-230-87-45-18$ & 2420 \\
\hline MBLL6 & $1530-550-530-260-230-95-60-45-22$ & 3322 \\
\hline MBLD7 & $1480-600-480-205-95-60-45$ & 2965 \\
\hline MBLL8 & $1530-560-280-95-45-22$ & 2532 \\
\hline MBLL9 & $1520-580-295-260-87-45-18$ & 2805 \\
\hline MBLD10 & $1480-540-240-87-45-18$ & 2410 \\
\hline MBLL11 & $1520-600-295-87-45-22$ & 2569 \\
\hline MBLC15 & $1550-215-135-87$ & 1987 \\
\hline MBLD17 & $1480-540-240-87-45-18$ & 2410 \\
\hline MBLD19 & $1480-510-215-87-45-18$ & 2355 \\
\hline MBLD21 & $1480-550-260-87-45-18$ & 2440 \\
\hline MBLL25 & $1520-560-280-95-80-45-22$ & 2602 \\
\hline MBLL26 & $1480-540-240-105-80-45-18$ & 2508 \\
\hline MBLL27 & $1480-560-280-87-45-18$ & 2470 \\
\hline MBLD35 & $1520-540-480-230-215-80-45-18$ & 3128 \\
\hline MBLD36 & $1520-540-240-80-45-22$ & 2447 \\
\hline MBLC38 & $1550-215-135-87$ & 1987 \\
\hline MBLC47 & 1530-560-280-240-135-87-80-45-22 & 2979 \\
\hline MBLC50 & $1520-560-280-80-45-18$ & 2508 \\
\hline MBLD51 & $1480-550-230-80-45-22$ & 2407 \\
\hline MBLD54 & $1550-540-240-230-87-80-45-22$ & 2794 \\
\hline MBLD55 & $1570-560-240-87-45-18$ & 2520 \\
\hline MBLD59 & $1550-560-240-87-80-45-22$ & 2584 \\
\hline MBLD63 & $1500-560-240-80-45-22$ & 2447 \\
\hline BLC21 & $1530-230-135-80$ & 1957 \\
\hline LL171 & $1480-510-280-105-45-18$ & 2438 \\
\hline M10 & $1480-560-280-180-160$ & 2660 \\
\hline ATCC 7962 & $1520-560-215-80-45-18$ & 2438 \\
\hline IL1403 & $1480-560-240-80-45-18$ & 2423 \\
\hline MG1614 & $1530-530-240-80-45-22$ & 2447 \\
\hline
\end{tabular}

a The name of strains was assigned according to phenotypical identifications. Expressions: MBLL and LL171: L. lactis subsp. lactis; MBLCBLC 21 and M10: L. lactis subsp. cremoris; MBLD: L. lactis subsp. lactis biovar diacetylactis.

originatingd from Turkey and characterized phenotypically. It was determined that four of them do not belong to L. lactis species. So, it was proven with this study that morphological and biochemical tests do not give reliable results for typing. For this reason, results obtained from phenotypic tests should be absolutely verified by molecular typing methods. PFGE was found suitable for both evaluation of genomic heterogeneity among the lactococcal strains and differentiation among interspecies. Also, PFGE results were confirmed by
$16 \mathrm{~S}$ rDNA sequence analysis. High heterogeneity was found among L. lactis strains isolated from Turkey. On the other hand, plasmid profiling results did not correspond with PFGE results. We conclude that the plasmid profiling is not sufficient for typing and also for evaluation of genomic heterogeneity of strains. Thus, results obtained from plasmid profiling should be used just to support PFGE results. In conclusion, morphologic and biochemical methods should be combined with molecular approaches for the purpose of strain-specific typing and also development of new starter cultures.

\section{Literature}

Akcelik M., P. Sanlıbaba and C. Tükel. 2000. Phage resistance in Lactococcus lactis subsp. lactis strains from traditional fermented milk products in Turkey. Int. J. Food Sci. Tech. 35: 473-481.

Anderson D.G. and L.L. McKay. 1983. A simple and rapid method for isolating large plasmid DNA from lactic streptococci. Applied and Environmental Microbiology. 46: 549-552.

Ayad E.H.E., A. Verheul, C. de Jong, J.T.M. Wouters and G. Smit. 1999. Flavour forming abilities and amino acid requirements of Lactococcus lactis strains isolated from artisanal and non-dairy origin. Int. Dairy J. 9: 725-735.

Beasley S.S. and P.E.J. Saris. 2004. Nisin producing Lactococcus lactis strains isolated from human milk. Applied and Environmental Microbiology. 70: 5051-5053.

Botina S.G., Y.D. Tsygankov and V.V. Sukhodolets. 2006. Identification of industrial strains of lactic acid bacteria by methods of molecular genetic typing. Russian Journal of Genetics. 42: 1367-1379. Boucher I., E.E. Mond, M. Parrot and S. Moineau. 2001. DNA sequence analysis of three Lactococcus lactis plasmids encoding phage resistance mechanisms. J. Dairy Sci. 84: 1610-1620.

Charteris W.P., P.M. Kelly, L. Morelli and J.K. Collins. 1997. Review article: Selective detection, enumeration and identification of potential probiotic Lactobacillus and Bifidobacterium species in mixed bacterial populations. International Journal of Food Microbiology 35: 1-27.

Delgado S. and B. Mayo. 2004. Phenotypic and genetic divercity of Lactococcus lactis and Enterococcus spp. strains isolated from Northern Spain starter-free farmhouse cheeses. International Journal of Food Microbiology 90: 309-319.

Demarigny Y., M. Dalmasso, A. Tonleu, V. Rigobello, E. Beuvier, M.H. Ly-Chatain and Y. Bouton. 2011. Influence of the backslopping practice on the microbial diversity of the Lactococcus population in a model cheesemaking. Food and Nutrition Sciences 2: 618-627. De Vuyst L. and B. Degeest. 1999. Heteropolysaccharide from lactic acid bacteria. FEMS Microbiol. Rev. 23: 153-177.

Dieye Y., S. Usai, F. Clier, A. Gruss and J.C. Piard. 2001. Design of a protein- targeting system for lactic acid bacteria. J. Bacteriol. 183: 4157-4166.

Erkus Kütahya O., M.J.C. Starrenburg, J.L.W. Rademaker, C.H.W. Klaassen, J.E.T. van Hylckama Vlieg, E.J. Smid and M. Kleerebezem. 2011. High-resolution Amplified Fragment Length Polymorphism typing of Lactococcus lactis strains enables identification of genetic markers for subspecies-related phenotypes. Applied and Environmental Microbiology 77: 5192-5198.

Fallico V., R.P. Ross, G.F. Fitzgerald and O. McAuliffe. 2012. Novel conjugative plasmids from the natural isolate Lactococcus lactis subspecies cremoris DPC3758: A repository of genes for the potential improvement of dairy starters. J. Dairy Sci. 95: 3593-3608. 
Farber J.M. 1996. An introduction to the hows and whys of molecular typing. J. Food. Prot. 59: 1091-1101.

Fernandez E., A. Alegria, S. Delgado, M.C. Martin and B. Mayo. 2011. Comperative phenotypic and molecular genetic profilling of wild Lactococcus lactis subsp. lactis strains of the L. lactis subsp. lactis and L. lactis subsp. cremoris genotypes, isolated from starter-free cheeses made of raw milk. Appl. Environ. Microbiol. 77: 5324-5335. Fujita Y., T. Okamoto and R. Irie. 1984. Plasmid distribution in lactic streptococci. Agriculture Biology and Chemistry. 48: 1895-1898. Giraffa G. and E. Neviani. 2000. Molecular identification and characterisation of food associated lactobacilli. Italian Journal of Food Science 4: 403-423.

Godon J.J., C. Delorme, S.D. Ehrlich and P. Renault. 1992. Divergence of genomic sequence between Lactococcus lactis subsp. lactis and Lactococcus lactis subsp. cremoris. Appl. Environ. Microbiol. 58: 4045-4047.

Holzapfel W.H., P. Haberer, R. Geisen, J. Björkroth and U. Schillinger. 2001. Taxonomy and important features of probiotic microorganisms in food and nutrition. American Society for Clinical Nutrition 73: 365-373.

Kahala M., M. Mäki, A. Lehtovaara, J.M. Tapanainen, R. Katiska, M. Juuruskorpi, J. Juhola and V. Joutsjoki. 2008. Characterization of starter lactic acid bacteria from the Finnish fermented milk product viili. J. Appl. Microbiol. 105: 1929-1938.

Kelly W.J., G.P. Davey and L.J.H. Ward. 2000. Novel sucrose transposons from plant strains of Lactococcus lactis. FEMS Microbiol. Lett. 190: 237-240.

Kelly W.J., L.J.H. Ward and S.C. Leahy. 2010. Chromosomal diversity in Lactococcus lactis and the origin of dairy starter cultures. Genome Biology and Evolutionary. 2: 729-744.

Le Bourgeois P., M. Lautier, M. Mata and P. Ritzenthaler. 1992. Physical and genetic map of the chromosome of Lactococcus lactis subsp. lactis IL1403. J. Bacteriol. 174: 6752-6762.

Le Bourgeois P., M. Lautier, L. van den Berghe, M.J. Gasson and P. Ritzenthaler. 1995. Physical and genetic map of the Lactococcus lactis subsp. cremoris MG1363 and Lactococcus lactis subsp. lactis IL1403 reveals a large genome inversion. J. Bacteriol. 177: 2840-2850. Le Bourgeois P., M.L. Daveran-Mingot and P. Ritzenthaler. 2000 Genome plasticity among related Lactococcus strains: Identification of genetic events associated with macrorestriction polymorphisms. Journal of Bacteriology 182: 2481-2491.

Liu S.L., A.B. Schryvers, K.E. Sanderson and R.N. Johnston. 1999. Bacterial phylogenetic clusters revealed by genome structure. Journal of Bacteriology 181: 6747-6755.

MacKay L.L. 1983. Functional Properties of plasmids in lactic streptococci. Antonie van Leeuwenhoek 49: 259-274.

Mannu L., A. Paba, M. Pes, R. Floris, M.F. Scintu and L. Morelli. 1999. Strain typing among enterococci isolated from home-made Pecorino Sardo cheese. FEMS Microbiology Letters. 170: 25-30.

Mannu L., A. Paba, M. Pes and M.F. Scintu. 2000. Genotypic and phenotypic heterogeneity among lactococci isolated from traditional Pecorino Sardo cheese. Journal of Applied Microbiology. 89: 191-197. Mannu L. and A. Paba. 2002. Genetic diversity of lactococci and enterococci isolated from home made Pecerino Sardo ewes' milk cheese. Journal of Applied Microbiology. 92: 55-62.

Marilley L. and M.G. Casey. 2004. Flavours of cheese products: metabolic pathways, analytical tools and identification of producing strains. International Journal of Food Microbiology. 90: 139-159. McCartney A.L. 2002. Application of molecular biological methods for studying probiotics and the gut flora. British Journal of Nutrition. 22: 29-37.

Mohania D., R. Nagpal, M. Kumar, A. Bhardwaj, M. Yadav, S. Jain, F. Marotta, V. Singh, O. Parkash and H. Yadav. 2008. Molecular approaches for identification and characterization of lactic acid bacteria. Journal of Digestive Diseases. 9: 190-198.
Mundt J.O. 1986. Lactic acid streptococci. pp. 1065-1066, In: Sneath P.H.A. (eds). Bergey's Manual of Systematic Bacteriology. MD: The Williams and Wilkins Co, Baltimore.

Nomura M., M. Kobayashi, T. Narita, H. Kimoto-Nira and T. Okamoto. 2006. Phenotypic and molecular characterization of Lactococcus lactis from milk and plants. J. Appl. Microbiol. 101: 396-405.

Odamaki T., S. Yonezawa, M. Kitahara, Y. Sugahara, J.Z. Xiao, T. Yaeshima, K. Iwatsuki and M. Ohkuma. 2011. Novel multiplex polymerase chain reaction primer set for identification of Lactococcus species. Letters in Applied Microbiology 52: 491-496.

O'Riordan K. and G.F. Fitzgerald. 1997. Determination of genetic diversity within the genus Bifidobacterium and estimation of chromosomal size. FEMS Microbiology Letters 156: 259-264.

O'Sullivan D.J. 1999. Methods for analysis of the intestinal microflora. pp:23-44, In: Tannock G.W. (eds). Probiotics. Horizon Scientific Press, Norfolk, UK.

Ozkalp B., B. Ozden, Y. Tuncer, P. Sanlıbaba and M. Akcelik. 2007. Technological characterization of wild-type Lactococcus lactis strains isolated from raw milk and traditional fermented milk products in Turkey. Dairy Science and Technology 87: 521-534.

Parente E. and T.M. Cogan. 2004. Starter cultures: General aspects. pp. 123-147. In: P.O.Fox (eds), Cheese: Chemistry, Physics and Microbiology. Elsevier, Oxford, United Kingdom.

Park D. 2007. Protocols for nucleic acid analysis by nonradioactive probes. Pp: 8. In: Hilario E. and J. MacKay (eds). Methods in Molecular Biology, Humana Press Inc., Totowa, NJ.

Passerini D., C. Beltramo, M. Coddeville, Y. Quentin, P. Ritzenthaler, M.L. Daveran-Mingot and P. Le Bourgeois. 2010. Genes but not genomes reveal bacterial domestication of Lactococcus lactis. Plos One 5: e15306.

Perez T., J.L. Balcazar, A. Peix, A. Valverde, E. Velazquez, I. de Blas and I. Ruiz-Zarzuela. 2010. Lactococcus lactis subsp. tructae subsp. nov. isolated from the intestinal mucus of brown trout (Salmo trutta) and rainbow trout (Oncorhynchus mykiss). International Journal of Systematic and Evolutionary Microbiology. 61: 1894-1898.

Pillidge C.J., L.M. Sheehy, A. Shihata, Z.Y. Pu, M. Dobos and I.B. Powell. 2009. Intragenomic 16S rRNA gene heterogeneity in Lactococcus lactis subsp. cremoris. International Dairy Journal 19: 222-227.

Psoni L., C. Kotzamanidis, M. Yiangou, N. Tzanetakis and E. Litopoulou-Tzanetaki. 2007. Genotypic and phenotypic diversity of Lactococcus lactis isolates from Batzos, a Greek PDO raw goat milk cheese. International Journal of Food Microbiology 114: 211-220.

Rademaker J.L.W., H. Herbet, M.J. Starrenburg, S.M. Naser, D. Gevers, W.J. Kelly, J. Hugenholtz, J. Swings and J.E.T. van Hylckama Vlieg. 2007. Diversity analysis of dairy and nondairy Lactococcus lactis isolates, using a novel multilocus sequence analysis scheme and (GTG) $)_{5}$-PCR fingerprinting. Appl. Environment. Microbiol. 73: 7128-7137.

Rantsiou K. and L. Cocolin. 2006. New developments in the study of the microbiota of naturally fermented sausages as determined by molecular methods. International Journal of Food Microbiology 108: 255-267.

Rohlf F.J. 1993. NSTSY-pc. Numerical Taxonomy and Multivariate Analysis System, Exeter Publishing, Setauket, NY.

Salama M.S., T. Mustafija-Jeknic, W.E. Sandine and S.J. Giovannoni. 1995. An ecological study of lactic acid bacteria: Isolation of new strains of Lactococcus including Lactococcus lactis ssp. cremoris. Journal of Dairy Science 78: 1004-1017.

Schleifer K.H., J. Kraus, C. Dvorak, R. Kilpper-Balz, M.D. Collins and W. Fisher. 1985. Transfer of Streptococcus lactis and related streptococci to the genus Lactococcus gen. nov. Syst. Appl. Microbiol. 6: 183-195. 
Siezen R.J., J.R. Bayjanov, G.E. Felis, M.R. van der Sijde, M. Starrenburg, D. Molenaar, M. Wels, S.A.F.T. van Hijum and J.E.T. van Hylckama Vlieg. 2011. Genome-scale diversity and niche adaptation analysis of Lactococcus lactis by comparative genome hybridization using multi-strain arrays. Microbial Biotechnology 4: 383-402.

Smit G., A. Verheul, R. van Kranenburg, E. Ayad, R. Siezen and W. Engels. 2000. Flavour formation from amino acids by lactic acid bacteria: Predictions from genome sequence analysis. Food Research International. 33: 153-160.

Sneath P.H.A. and R.R. Sokal. 1973. Numerical Taxonomy: The principles and practice of numerical classification. Freeman, San Francisco.

Tanskanen E.I., D.L. Tulloch, A.J. Hillier and B.E. Davidson. 1990. Pulsed-field gel electrophoresis of SmaI digest of lactococcal genomic DNA, a novel method of strain identification. Applied and Environmental Microbiology. 56: 3105-3111.

Tran K.T.M., B.K. May, P.M. Smooker, T.T.H. Van and P.J. Coloe. 2011. Distribution and genetic diversity of lactic acid bacteria from traditional fermented sausage. Food Research International. 44: 338-344.
Ulrich A. and T. Müller. 1998. Heterogeneity of plant-associated streptococci as characterized by phenotypic features and restriction analysis of PCR-amplified 16S rDNA. J. Appl. Microbiol. 84: 293-303. van Kranenburg R., M. Kleerebezem, J.E.T. van Hylckama Vlieg, B.M. Ursing, J. Boekhorst, B.A. Smit, E.H.E. Ayad, G. Smit and R.J. Siezen. 2002. Flavour formation from amino acids by lactic acid bacteria: Predictions from genome sequence analysis. International Dairy Journal. 12: 111-121.

Ward A.C., A.J. Hillier, B.E. Davidson and I.B. Powell. 1993. Stability analysis of the Lactococcus lactis DRC1 lactose plasmid using pulsed field gel electrophoresis. Plasmid 29: 70-73.

Ward L.J.H., H.A. Heap and W.J. Kelly. 2004. Characterization of closely related lactococcal starter strains which show differing patterns of bacteriophage sensitivity. J. Appl. Microbiol. 96: 144-148. Williams A.G., J. Noble and J.M. Banks. 2001. Catabolism of amino acids by lactic acid bacteria isolated from Cheddar cheese. Int. Dairy J. 11: 203-215.

Yeung P.S.M., C.L. Kitts, R. Cano, P.S. Tong and M.E. Sanders. 2004. Application of genotypic and phenotypic analyses to commercial probiotic strain identify and relatedness. J. Appl. Microbiol. 97: 1095-1104. 